\title{
Device for obtaining samples of intestinal contents for microbiological and biochemical examinations
}

\author{
I. SKÁLA AND J. ŠIMÁČEK \\ From the Institute of Human Nutrition, Prague-Krč, Czechoslovakia
}

Investigations into the microbiology of the intestinal flora are hampered by difficulties associated with obtaining intestinal contents for examination. The best method, because it is direct, is to take samples during abdominal operations either by puncture or from the open intestine, but as this procedure involves laparatomy, it is the exception rather than the rule.

A common method is the collection of specimens of the gastrointestinal contents by aspiration using different types of tube. The advantage is ready accessibility, but there is the problem as to what extent the specimens truly reflect the ecology of the small intestine and to what extent the contents are contaminated by those of the more proximal parts of the gastrointestinal tract through which the tube travels during its passage.

An obstacle to detailed and more accurate examinations is also the fact that the intestinal content which thus enters the tube without control distorts also the chemical composition of small specimens. This may be particularly disturbing when specimens are withdrawn from the more distal portions where it is usually possible to obtain only small specimens by aspiration. Some authors therefore inject through the tube sterile physiological saline which they aspirate immediately. Thus they rinse the intestine at the site where the specimens are collected but render quantitative evalution impossible. The composition of the aspirated specimens is also distorted because the more viscous components adhere to the walls of the tube.

These interfering factors can be eliminated by introducing into the tract a capsule manipulated from outside which opens at the site where the sample is to be taken and after the specimen has been taken closes again. On this principle capsules were designed which when swallowed pass into the small intestine. There a specimen of the intestinal content is taken (the capsule is operated from outside) and the capsule is excreted naturally. In the speci- men, however, digestion proceeds as well as reproduction of microorganisms, and thus before the capsule is excreted from the digestive system the composition of the specimen is altered. Another serious objection to these devices is that it is impossible to assess the position of the capsule at the time when the specimen is collected. Therefore devices based on this principle are not used in practice.

A new approach are the capsules designed by Henning, Zeitler, and Neugebauer (1958) and by Shiner (1963). In Shiner's device is a hollow capsule attached to the tube, the inner space of which is closed while the tube is inserted and removed. At the desired site the inner space of the capsule opens by suction and the intestinal contents are aspirated. After aspiration the capsule closes again with the aspirated specimen.

Our device is based on a similar principle and is a modification of our intestinal biopsy tube (Skála, Vulterinová, and Simáček, 1964). The hollow head fixed to the tube is closed while the tube is inserted and removed and opens only at the site of aspiration. The specimen of the intestinal contents remains inside the head and can be analysed after removal. The advantage of this device is its simple character, reliability, and the possibility of obtaining specimens of sufficient volume.

\section{DESCRIPTION OF THE TUBE}

The cylinder-shaped tube (Figs. 1 and 2$), \sqrt{ } 21 \mathrm{~mm}$ long and $9 \mathrm{~mm}$ wide, is made from corrosion-proof hardened steel and consists of a head (1) with eight circular openings (11) with a diameter of $1 \cdot 2 \mathrm{~mm}$, a lid (2) which is screwed to the head and provided at the opposite end with an orifice (3) for fitting the tube.

In the cylindrical space of the head is a piston (4) with a stop (7) fixed to the piston by a nut (8) with cut grooves (9). The piston has suction canals (6) which enter the hollow space of the piston. The whole subgroup of the piston is held by a spring (10). 


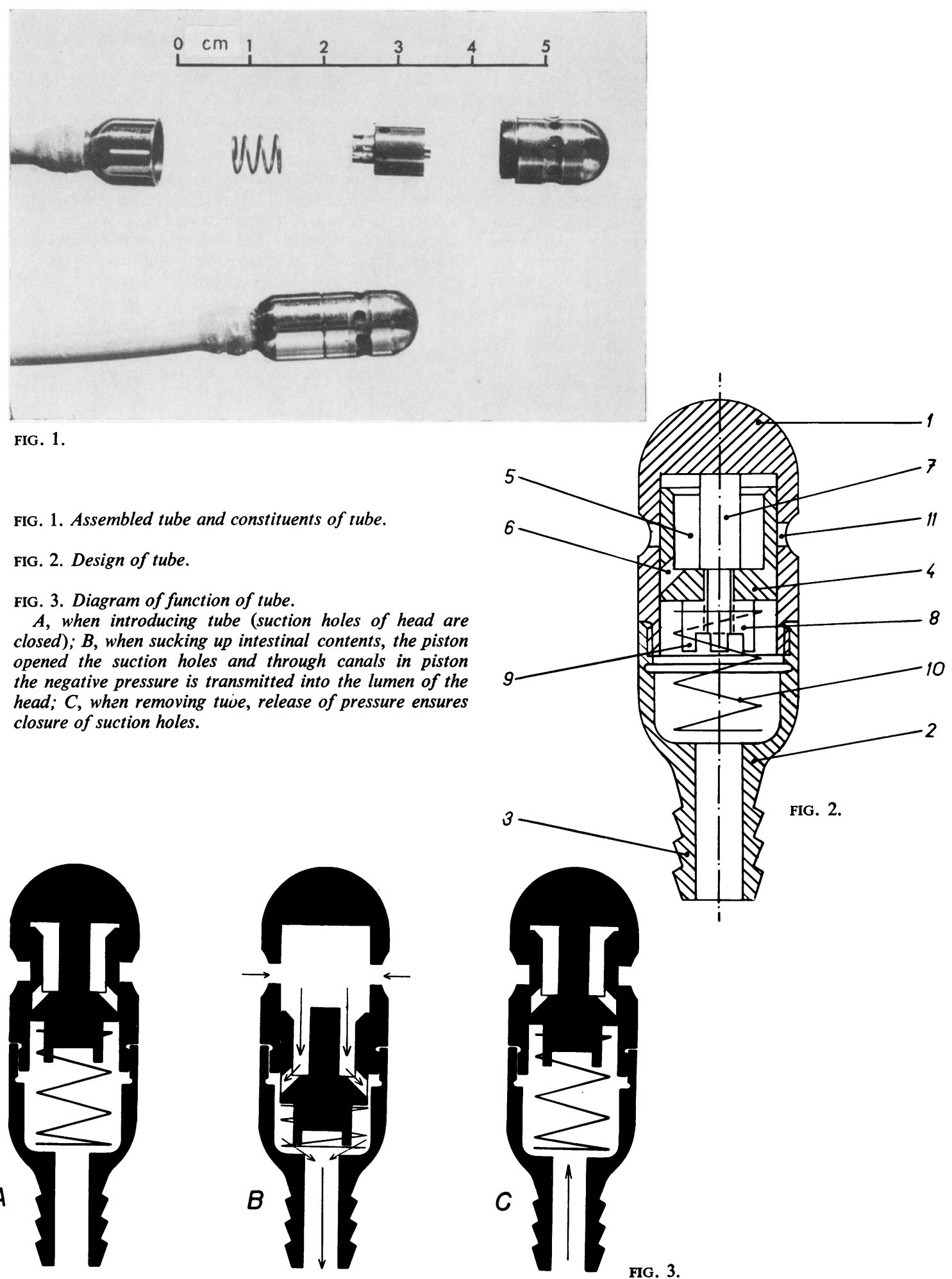




\section{METHOD OF USE}

Before use the tube is sterilized by boiling or in an autoclave and assembled under sterile conditions. It is introduced under $x$-ray control in the usual way into the desired portion of the intestine, taking all precautions to ensure sterility. The piston is kept in the position at rest by the spring (Fig. 3) and keeps the suction holes of the head closed. This prevents the contents of the digestive tract from penetrating the tube. The sample is collected by sucking up air with a syringe $(20-50 \mathrm{ml})$ into the lumen of the tube. As a result of the negative pressure the piston passes to the lid, presses the spring and releases the suction holes in the head. In this position, through the canals of the piston, the negative pressure is transmitted into the lumen of the capsule and the intestinal contents are aspirated (Fig. 3). The openings are in a circular groove on the circumference of the head which prevents the tube from adhering to the intestinal mucosa. When we stop sucking the spring returns to the position at rest. Thus the holes in the head are closed again. The return of the piston to the position at rest, and thus reliable closure of the openings, is achieved by slight overpressure created in the tube by means of the syringe used (Fig. 3). The entire procedure for collecting specimens can be repeated as desired.

After removing the tube we clean its surface under sterile precautions, unscrew the head and remove the intestinal contents, which are mainly in the lumen of the piston. During prolonged aspiration part of the contents also penetrates the lumen of the tube.

After use the tube is carefully cleaned by rinsing and mechanical cleaning. It is kept in refined mineral oil. Due attention must be paid to cleaning as this alone can prevent corrosion of the lumen of the head and piston. Corrosion by acid gastric juices is the main cause of disorders and reduces the reliability of the instrument.

\section{REFERENCES}

Henning, N., Zeitler, G., and Neugebauer, I. (1958). Über eine Darmpatrone zur Entnahme von Dünndarminhalt für bakteriologische Untersuchungen. Münch. med. Wschr., 100, 1858-1860.

Shiner, M. (1963). A capsule for obtaining sterile samples of gastrointestinal fluids. Lancet, 1, 532-533.

Skála, I., Vulterinová, M., and Simáxek, J. (1964). Biopsy intestinal tube (in Czech). Cs. Gastroent. Výž., 18, 497-500. 